Short Communication

\title{
Saccharin-assisted Galvanostatic Electrodeposition of Nanocrystalline FeCo Films on a Flexible Substrate
}

\author{
Setia Budi*, Rizqi Aulia Tawwabin, Ucu Cahyana, Afrizal, Maria Paristiowati \\ Department of Chemistry, Faculty of Mathematics and Sciences, Universitas Negeri Jakarta, Jl. \\ Rawamangun Muka, Jakarta Timur 13220, Indonesia \\ *E-mail: setiabudi@unj.ac.id
}

doi: $10.20964 / 2020.07 .74$

Received: 1 March 2020 / Accepted: 27 April 2020 / Published: 10 June 2020

\begin{abstract}
The electrodeposition of functional materials on a flexible substrate has become an interesting topic because of the current development of flexible devices, called flexible technology, for various electronic applications. This study investigated FeCo film electrodeposition on a flexible polyethylene coated with indium tin oxide using the galvanostatic technique. The obtained FeCo films have a very fine crystallite size with a uniform surface morphology that changed remarkably upon introduction of a saccharin additive and upon increasing the deposition temperature. The effect of the saccharin concentration and deposition temperature on the current efficiency and anomalous co-deposition of FeCo was discussed. In this work, electrodeposition from an electrolyte containing $1 \mathrm{~g} / \mathrm{L}$ saccharin at a very high current efficiency and a low deposition temperature was successfully achieved. The obtained composition ratio indicated that saccharin could reduce the anomalous co-deposition of $\mathrm{Fe}$ and $\mathrm{Co}$. This phenomenon was also observed at a high deposition temperature. These results convincingly show the high current efficiency and reduced anomalous characteristic of the saccharin-assisted electrodeposition of FeCo.
\end{abstract}

Keywords: High current efficiency electrodeposition, anomalous co-deposition, galvanostatic technique, saccharin additive, nanocrystalline FeCo

\section{FULL TEXT}

(C) 2020 The Authors. Published by ESG (www.electrochemsci.org). This article is an open access article distributed under the terms and conditions of the Creative Commons Attribution license (http://creativecommons.org/licenses/by/4.0/). 